This is a very rich book and prompts few criticisms. The book examines a period of about 250 years and, although Fosi often observes changes, chronology and change is not clear. Cases from the early eighteenth century often appear next to sixteenth century ones. On similar grounds, it would have made more sense to place the last chapter on papal propaganda at the beginning of the book rather than the end. Not only would this have been more chronological but the reader could then observe for himself the gap between ideals and realities in the numerous cases discussed in the central chapters. But these are minor quips in a brilliant book that offers so much, so clearly, in so few pages.

ANTHONY F. D'ELIA, Queen's University

\title{
Frye, Susan.
}

\section{Pens and Needles: Women's Textualities in Early Modern England.}

Philadelphia: University of Pennsylvania Press, 2010. Pp. xx, 302. ISBN 978-08122-4238-6 (hardcover) \$65.

In Sociable Letters (1664), Margaret Cavendish, Duchess of Newcastle, imagines herself at a feast celebrating poetic wit. As she enters the banquet, the sole woman on the guest list, she marvels at the intricately stitched "Hangings of Conception" adorning the walls and the tablecloths woven from the delicate threads of poets' brains. By her own admission, Cavendish was not adept with needle and thread. Yet, throughout her prolific writings, textile blurs insistently with text, needle with pen, in carefully "Wrought Works" that situate Cavendish's literary pursuits as a valid alternative to domestic activities and as a similarly virtuous mode of creative self-expression. While she may have been a failed "Spinster in Huswifery," she was a self-professed "Spinster in Poetry."

Susan Frye's splendid study takes as its focus the rich intersections between writing, needlework, and visual design that animate Cavendish's imaginary banquet and that were pivotal to early modern English thought. Troubling the long-standing critical binary that has tended to divorce the (masculine) pen from the (feminine) needle, Frye reads women's writings alongside stunning examples of embroidery and painting that testify to the important interrelationship between women's verbal and visual textualities in 
the sixteenth and seventeenth centuries. Rigorously researched, wide-ranging, and lavishly illustrated, Pens and Needles provides striking evidence of the "materiality of women's agency" (14) in early modern England. Women used their "works" actively to represent their experiences and to foster familial and sociopolitical connections.

The first section of the book compellingly illustrates the communicative significance - as well as the astonishing scope and beauty - of the objects produced with women's pens and needles. In Chapter One, Frye traces the "political textualities" (30) manifested in the young Elizabeth Tudor's embroidered manuscript translations and early portraiture, in Mary Stuart's strategic iconography, and in Bess of Hardwick's embroidery and architectural innovations. Each of these material case studies registers a careful crafting of political identity and kinship. Of particular note is Frye's important discovery at Hardwick Hall of an appliquéd portrait of Mary Stuart, attired in her characteristic white mourning, as Chastity. The portrait commemorates Bess of Hardwick's relationship with Mary even as it highlights the Countess's skill in creating textiles that strategically affirm her social and dynastic position.

One of the many strengths of Frye's study is its attention to women's textualities across social classes. Chapter Two showcases the work of three lesser-known early modern writers and artisans: Levina Teerlinc, Jane Segar, and Esther Inglis. On the margins of power, these women used their exquisite works to attract patronage. Teerlinc's miniatures and illuminated manuscripts, produced for Henry VIII, Edward VI, Mary I, and Elizabeth I, reveal her adeptness at negotiating the politics and fluctuating religious practices of the Tudor courts. Jane Segar's fascinating calligraphic manuscript, The Prophecies of the Ten Sibills, presented as a gift to Elizabeth I in 1589, makes use of cipher to situate Segar as a prophetic translator intimately linked to the virginal queen celebrated in her text. This impressive chapter concludes with a valuable exploration of Esther Inglis's jewel-like manuscripts. Attending to each stage of the fabrication of her books and confidently portraying herself as a skilled author, Inglis claims a place within the masculine sphere of book production.

In Chapter Three, Frye focuses on domestic needlework - notably the spot sampler, the band sampler, and the embroidered pictures of female exemplars in "Hebrew samplers" - to show how women used their needles to create emotional and narrative portraits and to cultivate alliances with a broader female community. The spot sampler, often passed down among 
family members and friends, constituted a "visual commonplace book" (122), a personal repertoire of stitches for larger embroidery projects. If sewing was a cultural imperative for women in the period, meant to demonstrate industry and substantiate virtue, it was also an activity that afforded women creative choice as they selected stitches and patterns for their band samplers and needlework pictures. The embroidered depictions of biblical female Worthies like Esther, Deborah, and Judith that Frye examines in this chapter encapsulate the "distinct, if limited, agency" (138) that women could encode through needlework. Popular embroidery patterns connected sewing women with these eloquent, powerful, and divinely sanctioned exemplars of often "gory but godly action" (157).

The second part of Pens and Needles shifts from material texts like the Hebrew samplers to consider how an awareness of visual textualities transforms our readings of text and/as textile in literary works. Chapter Four probes the eroticization of textile production and exchange through an insightful analysis of the handkerchief that plagues Othello and the hangings, bloody cloth, and disguises that propel the action in Cymbeline. Desdemona and Innogen are conflated - often violently - with cloth that becomes a material stand-in for their supposedly soiled bodies. While Innogen, unlike Desdemona, ultimately survives to assert a certain degree of control over Cymbeline's textiles, both plays capitalize on the close associations among cloth, sexuality, and gendered subjectivity in the period.

Textiles figure just as prominently within the "landscape of female textualities" (193) integral to Mary Wroth's Urania, the focus of Chapter Five. Frye elucidates the rhetorical function of textiles in Wroth's romance, productively tracing early modern analogies between verbal eloquence, artifice, and sartorial choice. For Wroth, already well attuned to the "politics of cloth" (197) within the Sidney circle, textiles - especially clothing — hold the power to deceive the eye and externalize emotion. While Wroth rarely figures her protagonists at their needles, clothing and other textiles ultimately emerge in Urania as fitting metaphors for the narrative construction of her romance.

Although not all early modern women enjoyed needlework or saw embroidery as a form of self-expression, Frye demonstrates the importance of considering pens and needles as closely interrelated creative vehicles that offered women from varied social positions the possibility of enacting agency, whether through an alphabet sampler or an unresolved two-volume romance. 
Persuasively interweaving verbal and visual textualities, Frye's elegantly wrought work enriches our understanding of women's subjectivities and rhetorical practices in the sixteenth and seventeenth centuries even as it makes a timely contribution to discussions of early modern English material culture.

KATHERINE R. LARSON, University of Toronto

\section{Giddens, Eugene.}

\section{How to Read a Shakespearean Play Text.}

New York: Cambridge University Press, 2011. Pp. ix, 187. ISBN 978-0-52171397-9 (paperback) \$28.95.

Eugene Giddens has written a very useful book and assigned it a misleading title. From the title, one would expect his book to concern itself with major thematic concerns like gender or religion, or major generic categories like comedy or tragedy. Giddens notes near the beginning of the third chapter (of four) that "As it would be impossible to contain all of the approaches to 'reading' a play text within a single book chapter, this section will outline some of the techniques available to scholars to help with encountering the originals" (106). This note could describe the book as a whole, which restricts itself to bibliography. Only the fourth and final chapter concerns itself with "Reading modern editions," and this largely shows "how editorial policy affects the text" (147). While How to Read a Shakespearean Play Text omits much of what affects the reading process outside bibliography, it by no means limits itself to Shakespeare. Chapter two, "The Features of a Play Text," includes sections on features found seldom or never in Shakespearean texts. Most of the third chapter works through a practical guide to editing, but mainly by reference to the works of James Shirley, of which Giddens is general editor. Much of this material possesses considerable interest, and it is certainly relevant to reading Renaissance play texts, but not to reading Shakespeare's in particular.

This observation is not meant to criticize the book as a whole, only the title. How to Read a Shakespearean Play Text succeeds as a survey of and introduction to the bibliographical investigation and editing of early modern play texts in general. At the bottom of his first page, Giddens defers to earlier 